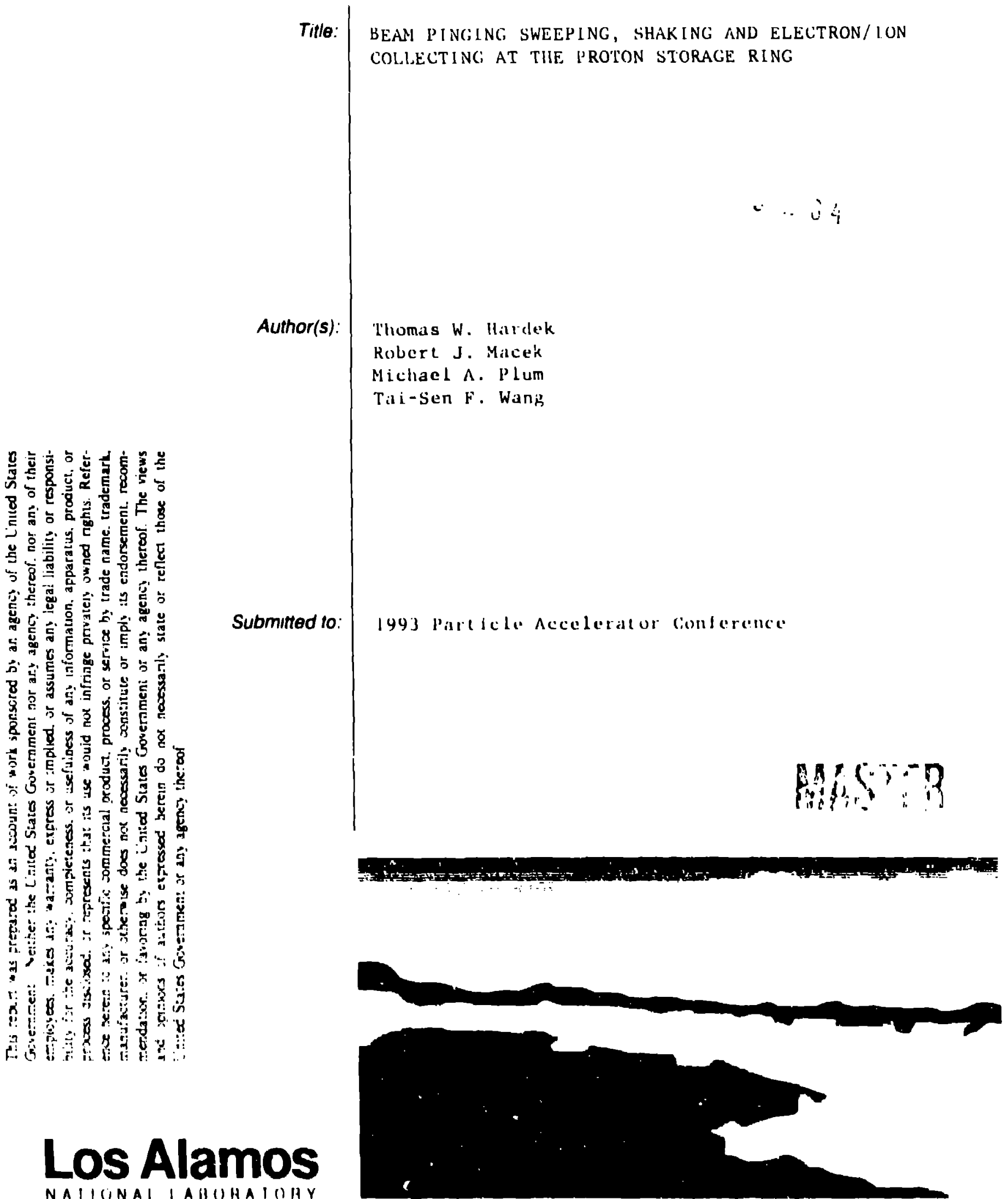

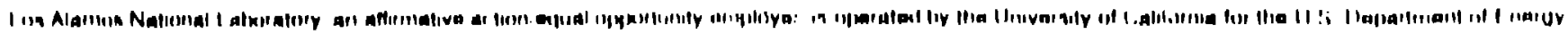

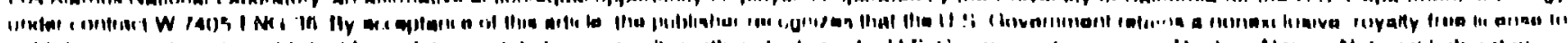

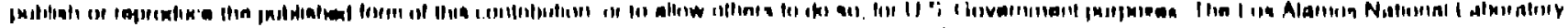

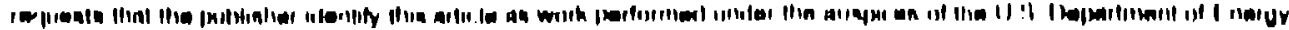




\title{
Beam Pinging, Sweeping, Shaking, and Electron/Ion Collecting, at the Proton Storage Ring*
}

\author{
T. Hardck, R. Macck, M. Plum, T.-S. Wang \\ Los Alamos National Laboratory \\ MS-H838, PO. Bux 1663, L.os Alamos, NM 87545 USA
}

\begin{abstract}
Abstrait
We have built, installed and tested a pinger [1] for use as a general diagnostic at the Los Alamos Ptoton Storage Ring (PSR). Two 4-m-long parallel-plate electrodes with a platte spacing of $10.2 \mathrm{~cm}$ provide kicks of up to $1.1 \mathrm{mrad}$. $\mathrm{A}$ pair of solid-stitc pulsers may be operated in a single-pulse mose for beam pinging (tune measurernents) or in a burst mole at up :0 $700 \mathrm{kHz}$ pulse rates for beam swecping. During our 1992 operating period we used the pinger for beam swecping, for beam sl iking, for measuring the tune shift, and we have used it as an ion chamber. Using the pinger as an ion chamber during production conditions has yiclded some surprising result
\end{abstract}

\section{INTRODUCTION}

In the past we have measured the horizontal lune at hight intensity by pulsing the extraction-kicker clectrodes at reduced voltages. We have; also acyuired additional horizontal datil by ohserving coherent motion proxluced by the charging operation for our Blumlein-configured extraction-kicker modulalors; however, there has !een no convenient why $(1)$ make a similar measurement in the vertica! plane. IJuring a lue;ik in our l(9)2 operaling perioxl we installied a set of vertical pinger electrodes $|1|$ in section 3 of the PSR. We are now calpable: of pinging the heam vertically and ubserving verticisl colserent motion.

III ilddilion In Ixeam pinging we also huve the ahility of swecpling beim from the spake belween bean hunches. ()peralliny, il a maxumum of IO kV our pulsers can nof Ienuve all the lxe:ImI in a single kick. We depend on severil kicks

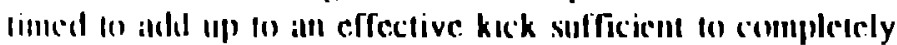
remeve the Ix'am. In practice we adjust the liracliomal lune: In $1 / 6$ and kick every o lurns. We have also operatled wilh a verticil lune of $1 / 4$ with a kick every 4 lurns.

like pinger chectrode:s may be ix binsed and used as

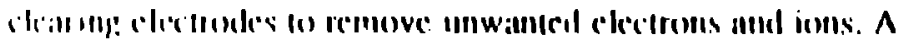

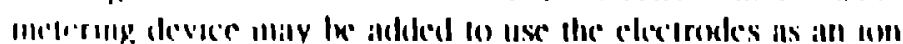

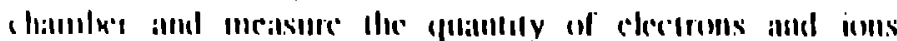

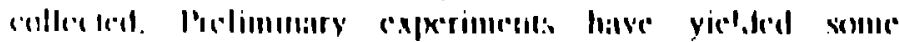
conlusully: resulss.

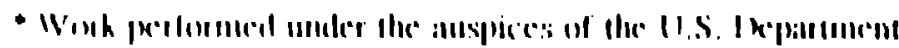
(1) H.ncris:
We present here an overvicw of some of the initial data we have collected in pinger and heam-sweeping experiments. We also present results from our nieasurement of the collected charge with the pinger operated as an ion chamber.

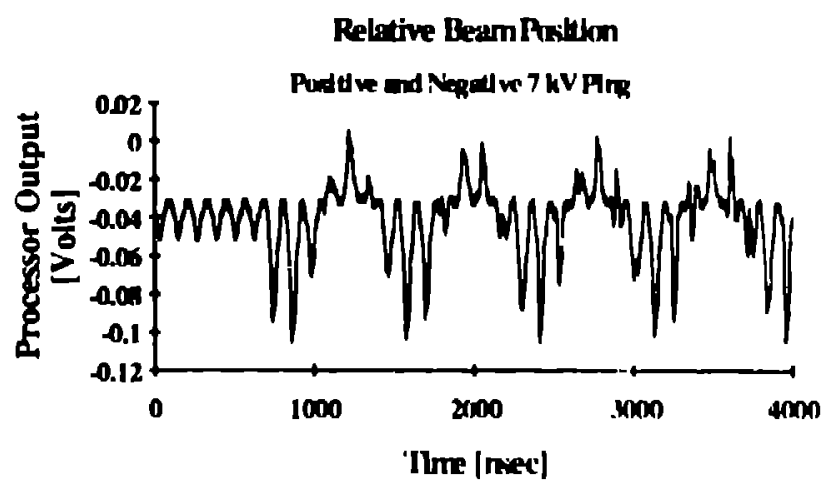

Figure I: Coherent Beaun Motion alter a 7 kV Ping

\section{BIIAM PINCIING;}

We (an provide positive and negative I0 kV pulses: timed to (xcur al any selected linke wilhin lhe ISSR accumulation cycle. "The pulse widlh is adjustahle from l|x|

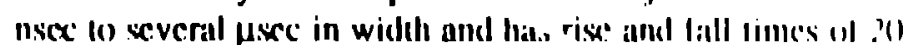
nsec. lior lx:an pinging we: adjusl the pulse widh (o) one l'Sk revolution perioxl (?(x) nsec) and time the kick wo ix s'ur as llic Ixam bunch passes llo: pinger elechenle. We call observe

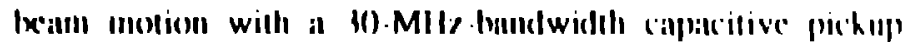
systeol or with strip-line prekups. The strup line pushup

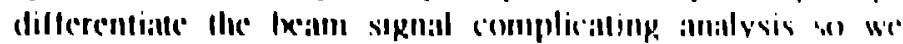

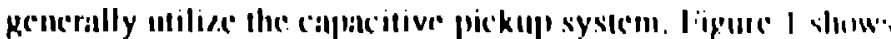

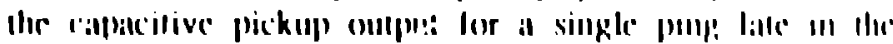

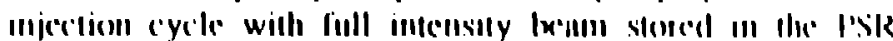

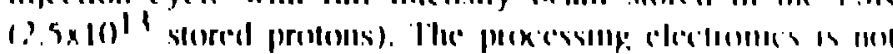

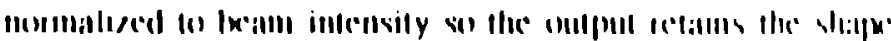

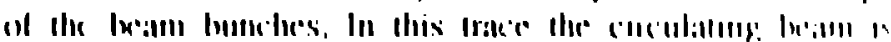

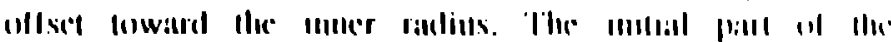

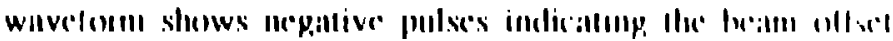

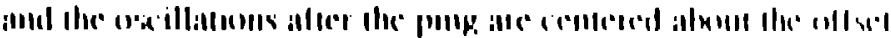

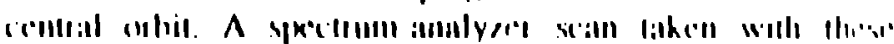


conditions gives sidebunds at 2.476 MIIz and $3.144 \mathrm{MH}$ with a neasured fevolution frequency of $2.808 \mathrm{MH}$. The resulting full intensity vertical tune is 2.119, compared to a lowintensily single-injected-hunch measured tune of 2.134.

\section{BEAM SWIII:PING}

In the beam sweeping mode we can provide a 100) nsec-long $10 \mathrm{kV}$-kick al a maximum rate of $7(0) \mathrm{kH}$. The revolution frecuency is $2.8 \mathrm{MH}$. so we can kick every four tums. For normal production : ie set the vertical tune to 2.17.3. ()nly a minor change is necessary to alter the fractional tune (1) 11.166 and generale a kick every six tums so we have chosen this scenario for our normal sweeping inode. The minimum available pulse widh is $\mathrm{l}(\mathrm{X})$ nsec (full width, half maximum). Figure 2 shows the result of several sequential sweeping pulses. We have set the injected beam bunch length (1) $I(x)$ nsec and have centered the kick on the heam bunch allowing our sweeping pulse to remove all of the in iected beatu. W( have nol longitudinally confined the heam so some lxeam remains at the leading and trailıng edges of the kick.

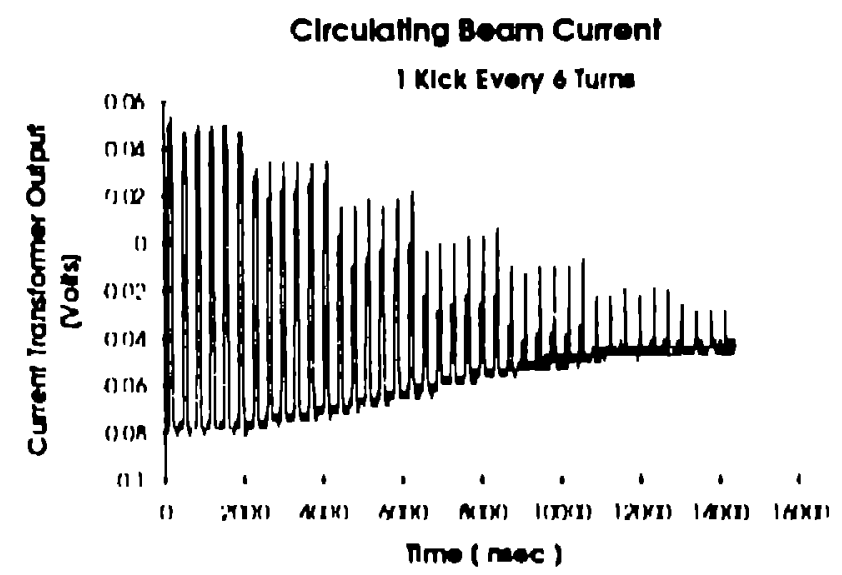

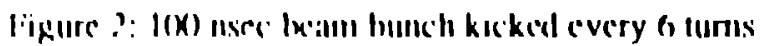

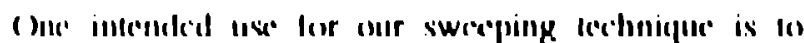
completely chear the space lxelween humedies of protons. ( )nly

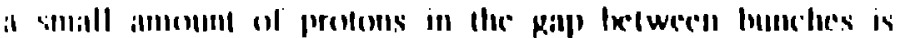

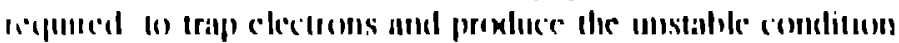

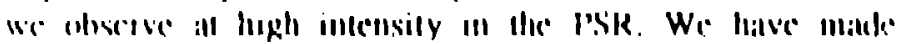

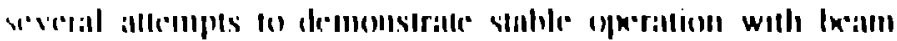

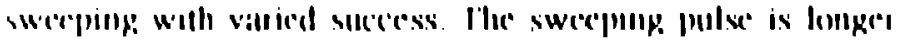

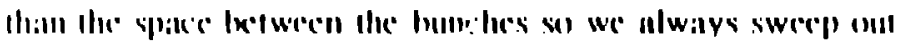

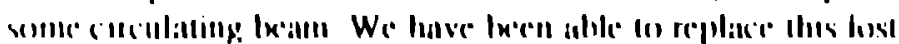

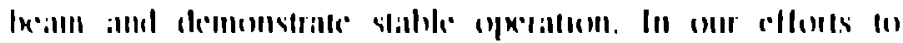

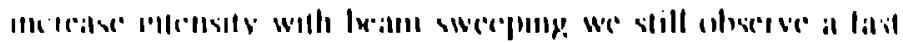

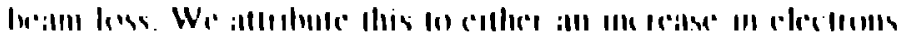

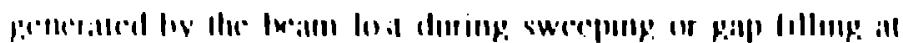

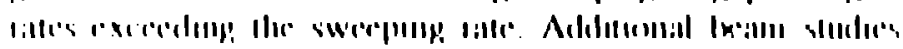

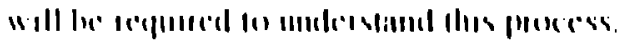

\section{BГAM SHAKING;}

During the 199) run periogl wie were ahle to (Irive an extraction-kicker electrode with a cw sinusoidal rf sig, al atl a frequency near the lowest horizontal tune freyuency. W': ohserved an increase in the instability threshold of about live percent. We have now repeated this experiment using the pinger electrocle and demonstraled a similar restult for the verical planc. Driving at about $25 \mathrm{MHz}$ at the $(x)$-wall level (into) a 50-ohm load at one end of the electroxle) resulted in an abrupt increaxe in vacuum chamber pressure. There seems to have been some sort of electrical breakdown at vollage: levels well helow the $10 \mathrm{kV}$ hold-olf capabiluy of our electrode system. We have yet to repeat the experiment without heant.

\section{ION CIIAMBIRR RESUI.TS}

We have also used the pinger clectrodes as an ion chamber hy biasing orie or both elecirodes, arul measuring the current dhus collected. Ions and electrons from residual gats ionization usually comprise the primary contribution trom such is measurement. (Oher contributuons include secondary enission of electrons due 10 interactions of the beam wilh the ix-an pipe and pinger electrokles, and protons from the halo of the leam stopping in the clectroxles. There are: also strong: (1.50) V peak-to-peak into .5) ohnss) ac-coupledl signals duc 10 the Ixam passing by the electroles. Tho minimize the clfect of

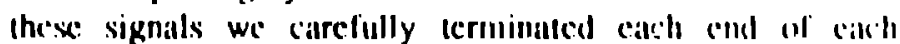
cleclrokle: into 50 (ohms, as shown on ligure 3.

We have tried vanious setups, includlug hasing ome electrode and mesisuring the courrent ons the other elcillokle,

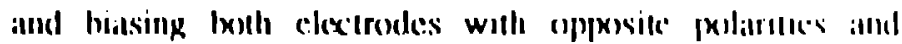
meisurmy the current on one of them. We hatve also tried fo supress the strong ac-coupled signal, due (1) lexall passulp? by

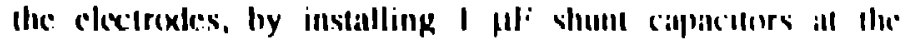

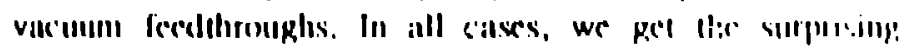
results shown in ligure 4 . Jor this fipure we have chesede Iwo

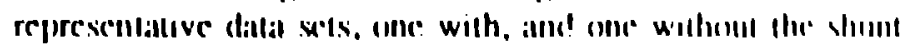

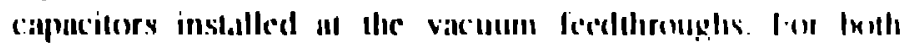

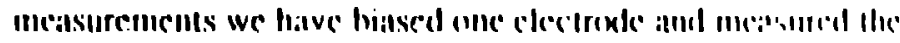

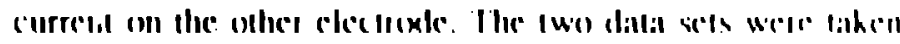
dun ing presluction: comblitions, but on defferent diss Wie ire

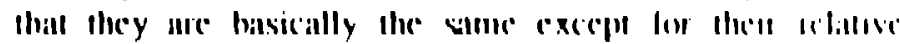

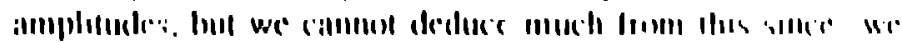

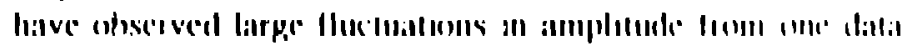

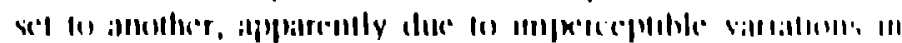

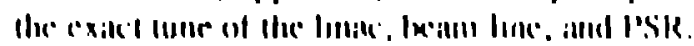

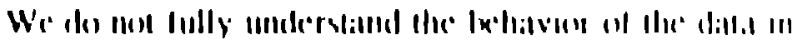

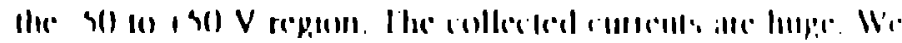

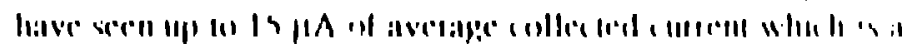

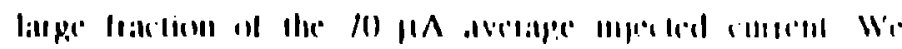

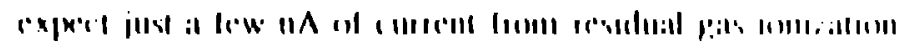

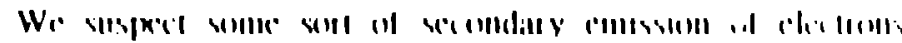


calused by the interactuons of the residual gals ions and eketrons with the beam prex walls and pinger celectrokles. The itrong ac-coupled signalis on the pinger electroxtes duc to the high-intensity heam pulses may contuibute to the unusual pakss in this datil. To eliminate this ciflect we tried injectong low-current de leam into the ring. Figure 5 slows the results (I) these me:asurents, taken at $4 \mathrm{H} \%$, with $2(x) \mu s$ of itcumulation and $5(x) \mu$ s of storage. In this ligure the error bars reprevent the range of current readings oheerved over a 30. second inteval. The selup was also a bil delferent from that slus'n in Iig. 4: The Ix)tem electrode was connecled direclly (1) a power supply, with no $5($ )-ohm terminations at either end, and the low-puss filler on the picoamencter was slightly different. This data is about what one would expect showing a gradual climh to a plateau at a couple thousand volts. We hopo that additional measurentents scheduled lor this sumimer will shed seme more light on our puzrling data.

\section{CONCLUSIONS}

We have a new diagnostic $t(x) l$ to study PSR proformance. Wi have thus far had only limited opportunitios (o) explore the uses of this new t(x)l and have generited some confusing hut interesting results. This year we hope fo clatrity these results and complete additional bean experinients, possibly including a detailed beam transfor function measurement.

\section{REFFRTNCIES}

11] "A Pinger System for the Los Alamos I'toton Storatge King", T. W. Hardek aml II, A. Thiessen, |w1)/ 'urticle" Acicelerator confercince' Proceeddings, pp. $8(6)-8(8)$.

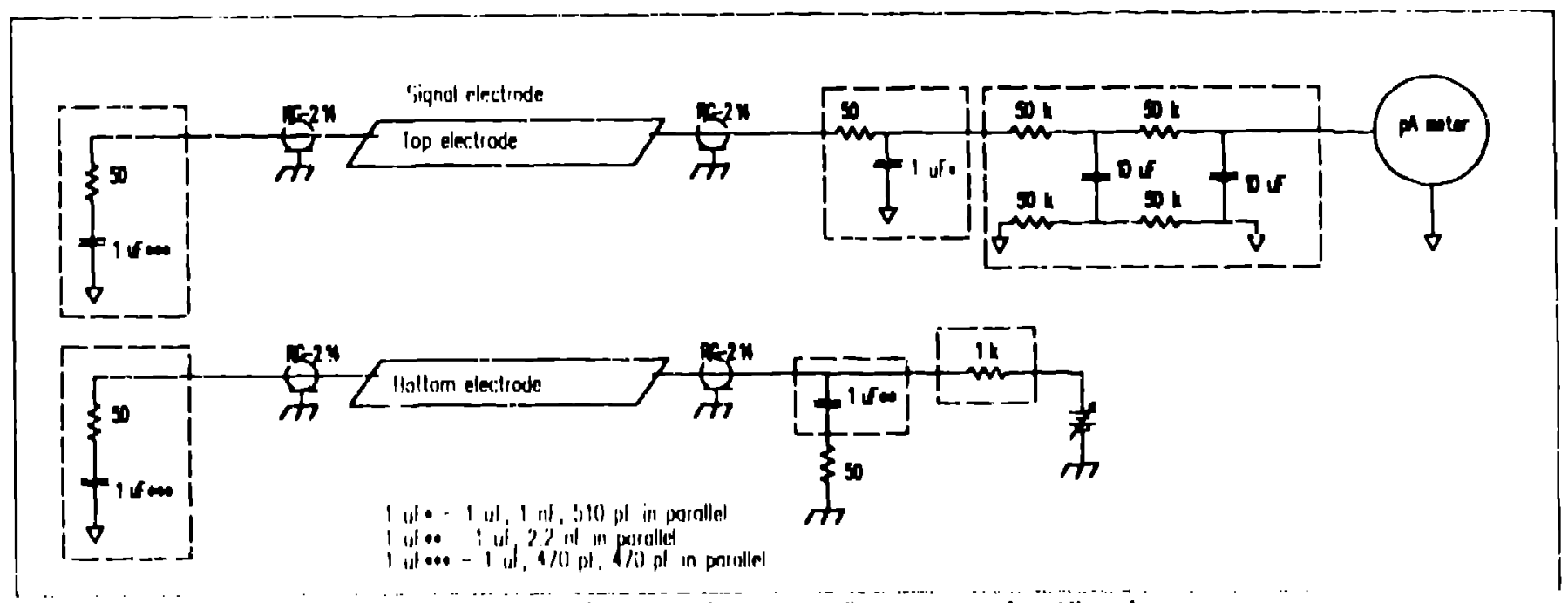

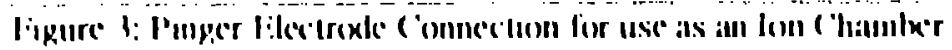

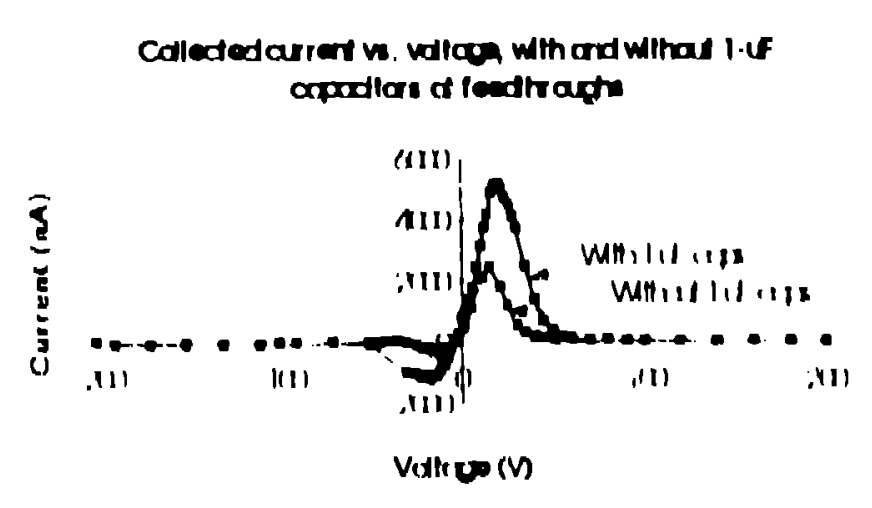

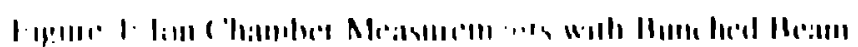

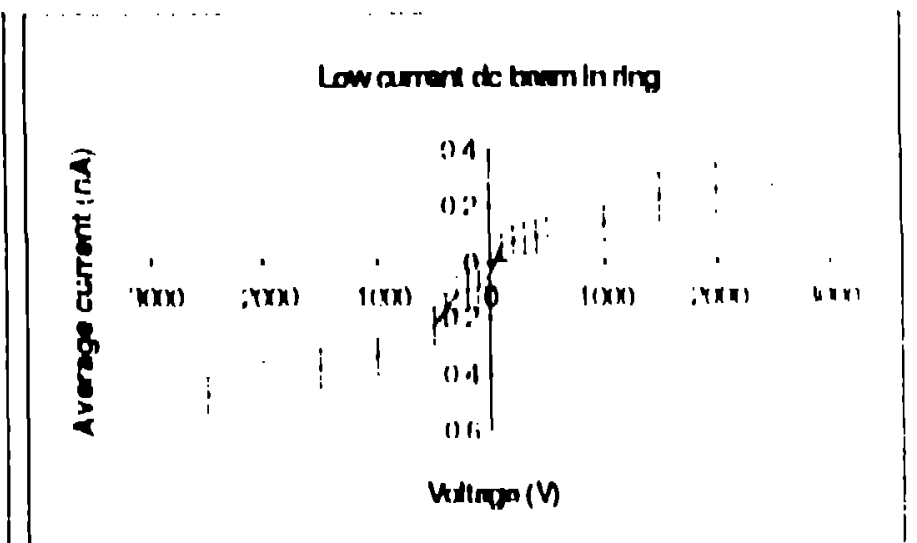

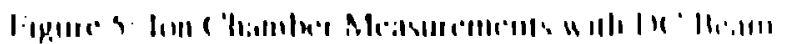

